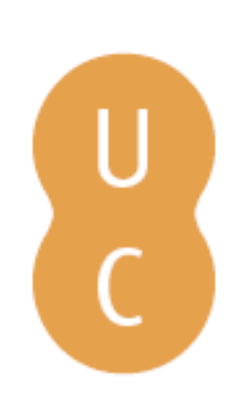

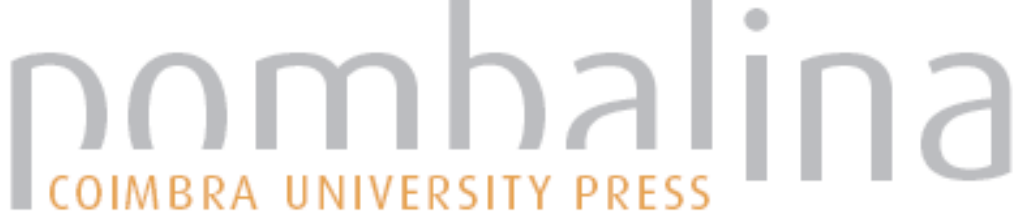

\section{O convento: uma leitura de Frei Luís de Sousa,de Almeida Garrett}

\author{
Autor(es): Magalhães, Gabriel \\ Publicado por: Imprensa da Universidade de Coimbra \\ URL \\ persistente: \\ URI:http://hdl.handle.net/10316.2/38687 \\ DOI: \\ DOI:http://dx.doi.org/10.14195/978-989-26-1164-8_10
}

Accessed : $\quad$ 26-Apr-2023 10:13:39

A navegação consulta e descarregamento dos títulos inseridos nas Bibliotecas Digitais UC Digitalis, UC Pombalina e UC Impactum, pressupõem a aceitação plena e sem reservas dos Termos e Condições de Uso destas Bibliotecas Digitais, disponíveis em https://digitalis.uc.pt/pt-pt/termos.

Conforme exposto nos referidos Termos e Condições de Uso, o descarregamento de títulos de acesso restrito requer uma licença válida de autorização devendo o utilizador aceder ao(s) documento(s) a partir de um endereço de IP da instituição detentora da supramencionada licença.

Ao utilizador é apenas permitido o descarregamento para uso pessoal, pelo que o emprego do(s) título(s) descarregado(s) para outro fim, designadamente comercial, carece de autorização do respetivo autor ou editor da obra.

Na medida em que todas as obras da UC Digitalis se encontram protegidas pelo Código do Direito de Autor e Direitos Conexos e demais legislação aplicável, toda a cópia, parcial ou total, deste documento, nos casos em que é legalmente admitida, deverá conter ou fazer-se acompanhar por este aviso. 
Gabriel Magalhães

Universidade da Beira Interior / Centro de Estudos Comparatistas

\section{O CONVENTO \\ UMA LEITURA DE FREI LUÍS DE SOUSA, DE ALMEIDA GARRETT}

Todos sabemos que o Frei Luís de Sousa é uma obra-prima - mas quase ninguém ama, do fundo do coração, esta peça de Garrett. Dá-se nas escolas: dá-se e esquece-se. Curiosamente o livro ficou, nestes últimos tempos, com perfis contemporâneos. Portugal é hoje em dia uma nação de ambiente trágico, muito semelhante à do drama de 1843 .

Existem, na atualidade do nosso país, famílias que ficam sem casa: que a "queimam" em jogos bancários. Existem desempregados de meia-idade, que morrem "de vergonha". E a nossa juventude é frágil e sem futuro - exatamente como Maria. Em cada momento que passa, sentimos o hálito de um espectro, de um morto-vivo, que de nós se aproxima. É estranho viver neste Portugal em forma de tragédia.

E contudo, apesar de as circunstâncias nos reenviarem para a peça de Garrett, continuamos a não a amar, embora a celebremos. Trata-se de uma celebração gélida: meramente de programa escolar. Porquê, se o Frei Luís de Sousa constitui o nosso melhor reflexo? Talvez porque não queiramos ver a verdade dura que vibra na peça. Mas, afinal, que verdade é esta?

\section{A galeria de espelhos}

De muitas formas se tem analisado este drama trágico, talvez para fugir à revelação austera que habita no seu fundo. E uma dessas maneiras de interpretar 
esta obra teatral de 1843 consiste em ler nela o indivíduo Almeida Garrett, seu autor. Trata-se de uma leitura um pouco "biografista": através da obra que escreveu, espreitamos a intimidade do escritor ${ }^{1}$.

Nesta perspetiva de estudo, acontece com frequência cometer-se o erro de pensar que Garrett se encenou numa determinada personagem do enredo ${ }^{2}$. Na realidade, ele escreveu-se a si próprio em todas elas. Garrett é Madalena, mas também é Manuel de Sousa Coutinho e é igualmente Telmo. Não há quase nada no Frei Luís de Sousa que não seja ele. A peça define-se como uma galeria de espelhos, em que tudo é Garrett. Tudo se constrói a partir do autor e dos seus dramas.

Neste sentido, os remorsos sentimentais garrettianos encontram-se em Madalena; a exemplaridade cívica do político surge-nos em Manuel de Sousa Coutinho ${ }^{3}$; a experiência da morte dos seus descendentes materializa-se na fragilidade de cristal de Maria. Até no patusco Telmo vivem as criadas da sua infância. Neste livro, Garrett está por todo o lado.

Por isso não é errado afirmar que, em Frei Luís de Sousa, lateja uma estranha colecção de possíveis heterónimos existenciais. De facto, João Baptista sempre tendeu para a heteronímia, transformando-se no Visconde de Almeida Garrett, metamorfoseando-se em Carlos ou João Mínimo. O autor de Viagens na Minha Terra esteve sempre na iminência de Pessoa, e legou a Eça de Queirós e aos seus amigos a possibilidade de um Fradique ${ }^{4}$

Ora, este jogo de heterónimos, ainda não totalmente conscientes de si mesmos, vive-se de um modo mais intenso em Frei Luís de Sousa. Talvez apenas D. João de Portugal nos surja como uma presença exterior ao dramaturgo. Mas no fundo esta figura também possui contornos biográficos: aquele espectro que pode voltar em qualquer momento representará talvez o célebre tio paterno, Frei

\footnotetext{
1 Um dos textos críticos clássicos sobre o Frei Luís de Sousa entendido como expressão velada de carácter autobiográfico é da responsabilidade de Álvaro Júlio da Costa Pimpão, O Frei Luís de Sousa de Almeida Garrett, Coimbra, Universidade de Coimbra, 1940, pp. 9-15. Esta tese teve considerável fortuna nas edições preparadas para o estudo da obra no ensino secundário.

2 Cf. Gabriel Magalhães, Garrett e Rivas: o Romantismo em Espanha e Portugal, vol. II, Lisboa, Imprensa Nacional-Casa da Moeda, 2009, pp. 44-45.

3 Esta identificação entre Garrett e Manuel de Sousa Coutinho é sublinhada por João Mendes: "Máscara, luz e chama, em Garrett" in Brotéria, vol. LXXXVII, n 11, Novembro de 1968, p. 511.

4 Cf. Gabriel Magalhães, "A dobradiça mágica: uma leitura extrema de Almeida Garrett" in Estar Entre, Salamanca, Editorial Celya, 2007, pp. 144-145.
} 
Alexandre da Sagrada Família, que assombrou a vida do autor através do modo severo como quase o forçou a um destino religioso. E esta peça tem algo de um velho pesadelo garrettiano, relacionado com a questão da sua vocação religiosa e revivido ficcionalmente.

Enfim, encontramo-nos perante um livro muito íntimo. É uma obra de interiores: o interior de uma família reflete o interior do seu autor. Porque todos nós, por dentro, somos, por assim dizer, uma estrutura familiar. Podemos agora perguntar: por que motivo se nos revelou o escritor de modo tão intenso neste trabalho?

A resposta parece bastante simples: porque quis, para este seu livro, verdade. E a verdade mais convincente de que um escritor é capaz nasce da sua intimidade. Foi, pois, com esses sedimentos pessoais que este drama se construiu. O objetivo era fugir da talha dourada literária, criando uma peça veraz, em carne viva.

Contudo, será uma terrível ingenuidade reduzir esta obra a uma consulta de psicanálise vivida publicamente. O Frei Luís de Sousa não é apenas uma confissão transposta para as suas personagens. Quem só ler isto no drama trágico de 1843 - dele leu quase nada. Como veremos, esta dimensão biográfica constitui apenas uma das camadas de uma peça que possui mais estratos geológicos.

\section{O prodígio estético}

A beleza do texto - este é outro dos pontos de vista possíveis ${ }^{5}$. Esqueçamos o autor e atentemos na obra. A criação artística parte sempre de uma impossibilidade. Como pode a bruta pedra tornar-se uma figura humana? De que modo acontece que as páginas de um romance se transformem num ecrã onde as palavras passam o filme de uma história? Como se explica que as tintas sobre uma tela cheguem a valer tanto como o vinco visual de uma paisagem?

A arte faz-se sobre abismos. Neste sentido, quanto mais impossível seja um projeto estético, mais virtualidades possui. Ora, a história de Frei Luís de Sousa é

5 A ideia de que o Frei Luís de Sousa é "a chave de uma abóbada perfeitamente construída" e, portanto, um trabalho estético maior foi detalhadamente explicada por Andrée Crabbé Rocha, O Teatro de Garrett: Tese de Doutoramento em Filologia Românica pela Universidade de Lisboa, $2^{\text {a }}$ ed., Coimbra, s. e., 1954, p. 151. 
completamente inadmissível. Como pode regressar o romeiro após tantos anos? De que modo se explica que sua mulher não o reconheça? Como justificar a morte de Maria, tão "romântica", no pior sentido da palavra: tão literariamente acontecida na altura em que seus pais professam?

Se a arte parte da sua impossibilidade, esta história de Manuel de Sousa Coutinho, tão incrível, permite que o fazer artístico se eleve ao cubo de si mesmo. E foi também por isso que Garrett colocou tanta verdade pessoal neste texto: não havia outro modo de, esteticamente, o salvar. Uma narrativa tão "artificial" só sobreviveria se nela transbordassem as entranhas do seu autor.

Quase todas as grandes obras partem, assim, de histórias "impossíveis": dez anos a combater à volta da cidade de Tróia, um homem que acredita ser cavaleiro andante, um poeta que é muitos poetas - eis alguns exemplos. Ora, a narrativa de Frei Luís de Sousa constitui uma história deste género - impossível, e por isso mesmo passível de motivar todo o tipo de jogos criativos.

É como se a ficção contada em cena apresentasse "feridas" de verosimilhança: feridas essas que serão cicatrizadas através da genialidade artística do autor. Quais são essas chagas, esses ossos partidos da história? O caráter exemplar de Manuel de Sousa Coutinho, talvez demasiado heroico, a figura de D. João de Portugal, que protagoniza um impossível regresso, e a morte de Maria.

Temos a impressão de que o texto se vai "quebrar" nestes pontos - e torna-se maravilhoso reconhecer a capacidade estética garrettiana para evitar essa rutura. Neste aspeto, as obras pictóricas presentes em cena funcionam como um gesso que sustém a verosimilhança daquilo que se vê em palco. Nesse gesso imagético tudo se solda.

Por exemplo, no caso de Manuel de Sousa Coutinho, é um retrato, presente logo no "Acto Primeiro", que lhe confere uma verdade indiscutível. O autor não se engana: essa figura precisava desse sublinhado de verosimilhança. E o facto de a tela arder ainda lhe sublinha mais a realidade: uma imagem toda em chamas torna muito mais real o sujeito nela representado.

Por isso, o incêndio no fim do primeiro ato não possui somente a dimensão simbólica habitualmente referida: não se trata apenas de anunciar o desfecho trágico da obra. Aquelas chamas desempenham também um papel estético importante, no que respeita à verosimilhança do drama. O fogo funciona como um sublinhado fluorescente do mundo encenado. Iluminados pelo incêndio, os 
perfis de Manuel, de Telmo, de Maria, de Madalena adquirem uma verdade definitiva - um contorno sólido inegável. E estamos prontos para o "Acto Segundo", em que um exército de retratos concederá verosimilhança a um cenário equívoco de filme de terror.

Com efeito, neste segundo ato, a dificuldade centra-se na figura de D. João de Portugal e no ambiente de mistério gótico que paira em cena ${ }^{6}$. Aumentando a inverosimilhança, aumenta também o número de retratos. As paredes alastram todas com documentação visual que certifica os factos, em si mesmos tão incríveis. Quanto menor é a credibilidade, mais telas dispõe o autor em palco.

O retrato de D. João de Portugal possui, neste aspecto, uma dimensão crucial. Por isso Maria e Telmo conversam sobre ele, assinalando-o ao espetador. Na verdade, será esse retrato que explicará a incapacidade que Madalena revela de reconhecer o seu esposo, quando este volta muito envelhecido. Assim, o primeiro ato gira à volta da imagem de Manuel de Sousa, e o segundo em redor da tela representando D. João de Portugal. Ambos os quadros são queimados: o do segundo marido de Madalena através das chamas - e o do romeiro por meio do incêndio verbal contido na sua célebre exclamação: "Ninguém!"

Eis precisamente outro momento extraordinário da peça: aquele em que o romeiro exclama "Ninguém!" É a voz da obra a admitir a sua ficcionalidade. Mas, nesse momento em que D. João de Portugal se permite esta confissão, aponta para o seu retrato passado - e essa ficcionalidade toda se condensa na tela, de tal modo que a figura atorial do romeiro fica crepitante de realidade. Um instante fabuloso do nosso teatro, este em que um personagem, ao revelar a mentira literária que o habita, lança essa sua ficcionalidade para uma imagem, ficando ele próprio absolutamente real e denso de verdade. E é deste modo que uma narrativa impossível se vai tornando credível através da maravilha da arte.

Falta construir a verdade da morte de Maria. Ao longo do texto, o autor vai espalhando sintomas: a fragilidade da jovem, a sua acuidade auditiva, a febre que nela se manifesta. No fundo, Frei Luís de Sousa é todo ele, ainda que clandestinamente, uma consulta médica - e quando a filha do infeliz casal morre em

6 A relação de Frei Luís de Sousa com uma certa literatura de terror foi estudada por Maria Leonor Machado de Sousa, "Frei Luís de Sousa e a literatura europeia" in AA. VV., Afecto às Letras, Lisboa, Imprensa Nacional-Casa da Moeda, 1984, pp. 483-489. 
palco, o diagnóstico já está feito, e o espetador, sem dar por isso, transformou-se num clínico que simplesmente certifica o óbito.

Desta forma uma história impossível se tornou viável. Muitos leitores ou espetadores assistem a este prodígio sem terem bem a noção da dificuldade, do árduo equilibrismo artístico que foi necessário para que a obra pudesse acontecer, com verosimilhança. Uma narrativa totalmente incrível desenrola-se perante os nossos olhos com a mesma naturalidade de uma cena de café.

É também por isso que surgem citações literárias no texto - aquele livro que Madalena lê no início, por exemplo. Não se trata apenas de homenagens a autores amados por Garrett. O objetivo é bem mais subtil: o dramaturgo quer que pensemos que a ficcionalidade se concentra nesses objetos - sendo pois real o mundo encenado que os contém. Um livro representado noutro livro, ou posto na cena de um drama, fica com a culpa de ser literatura - enquanto que o texto que contém esse livro, ou o drama em que ele surge, se ilibam dessa mesma culpabilidade. Em Frei Luís de Sousa, as citações de Garrett constituem também um desejo de que o seu trabalho apareça com a consistência do mundo real, ficando a ficção recluída nos textos citados.

E como golpe final de toda esta vontade de verosimilhança surge o título: Frei Luís de Sousa - um modo de, referindo um nome concreto da nossa história literária, dar historicidade à matéria, tão fantástica, representada no palco. Este título contamina de verdade a peça, tal como o fazem os retratos, as chamas, as citações literárias ou o cuidadoso diagnóstico da enfermidade de Maria ${ }^{7}$.

\section{Uma radiografia portuguesa}

Algo absolutamente extraordinário, neste drama trágico de 1843, é o facto de que tudo o que nele se lê de uma certa maneira - pode ser lido de um modo

Deve referir-se que, num trabalho clássico, Wolfgang Kayser interpretou o título da obra como um sinal do otimismo de fundo deste texto dramático: "Interpretação de Frei Luís de Sousa" in Análise e Interpretação da Obra Literária. Introdução à Ciência da Literatura, trad. de Paulo Quintela, vol. II, Coimbra, s. e., 1970, pp. 285-300. 
completamente diferente, e ambas as leituras são corretas $^{8}$. Encontramo-nos perante um texto estranho, como que escrito em muitos idiomas, embora tenha sido redigido numa única língua.

Este aspecto da multiplicidade de sentidos de Frei Luís de Sousa sublinha-se de um modo particular quando nos apercebemos de que as personagens da obra (que, como vimos, representavam facetas do seu autor) também refletem dimensões do nosso país. Os carateres do drama podem ser lido em termos "autoriais" - mas também em termos "nacionais".

Madalena, por exemplo, contém os remorsos garrettianos - mas também personifica esse "medo de existir" que José Gil detetou no nosso Portugal contemporâneo?. Na esposa de Manuel de Sousa Coutinho, Garrett colocou um traço profundo da nossa cultura, da nossa maneira de ser: este estranho sentimento de culpa com que somos portugueses. No fundo, Madalena não sente remorsos apenas por ter amado o seu segundo marido quando o primeiro ainda vivia com ela. Nessa culpa - e sobretudo no modo obsessivo como essa culpabilidade regressa -, sentimos esta outra culpa enigmática com que vivemos a portugalidade que vamos sendo. Não foi Alexandre O'Neill quem afirmou ser Portugal um remorso ${ }^{10}$ ? Ora, isso já o afirmara Garrett, através da figura de Madalena.

Mas, neste retrato nacional que o Frei Luís de Sousa desenha, encontramos ao lado de Madalena outra figura: Manuel de Sousa Coutinho. Este representa, em positivo, aquilo que a sua mulher encena em negativo. No pai de Maria, surge-nos a coragem portuguesa, a capacidade de aventura - por outras palavras: a iniciativa que levou a cabo os Descobrimentos, e todas as nossas maiores obras.

Assim, neste casal se configuram as duas pulsões fundamentais da nossa cultura, da nossa história: o pólo positivo do agir, materializado em Manuel, contrasta com o pólo negativo do recear, personificado em Madalena. Somos um país que parte e que fica: uma nação que se lança e se imobiliza. O impulso

8 Esta polissemia radical do drama trágico de 1843 foi tratada, entre outros, por Luciana Stegagno Picchio, "Interprétation d'interprétations: le Frei Luís de Sousa de Garrett" in La Méthode Philologique, II, Paris, Fundação Calouste Gulbenkian/Centro Cultural Português, 1982, pp. 263-277.

9 Cf. José Gil, Portugal, Hoje - O Medo de Existir, Lisboa, Relógio d’Água, 2007.

10 Trata-se dos célebres versos, incluídos no poema "Portugal", que integra a colectânea Feira Cabisbaixa, de 1965: "Portugal: questão que eu tenho comigo mesmo,/Golpe até ao osso, fome sem entretém,/Perdigueiro marrado e sem narizes, sem perdizes,/Rocim engraxado, feira cabisbaixa,/ Meu remorso,/Meu remorso de todos nós...". 
de avançar encontra-se no pai de Maria - o de ficar, em sua mãe. E este casal é Portugal.

Tal como Maria também é imagem da nossa pátria: na filha de Madalena e de Manuel, consubstancia-se toda a fragilidade de que se reveste sempre o futuro do nosso país. Porque esta menina simboliza o porvir português em forma de pessoa. E esse futuro é frágil, continuamente problemático. Maria representa os horizontes lusitanos, tantas vezes manchados por uma doença secreta. Também hoje os nossos jovens são Marias. O nosso presente está cheio de Marias: pessoas novas mal preparadas para aquilo que as espera. A configuração débil da filha de Madalena - é a mesma presença frágil das nossas filhas e dos nossos filhos. O futuro do nosso país perfila-se como a constante, a inquietante possibilidade de uma doença qualquer.

Entretanto, o povo representa-se em Telmo: uma massa popular algo amorfa, que insiste nas suas superstições, que "tem lá a sua ideia". Este povo é como um peso morto: quer na obra, quer na realidade do país. Sem dúvida: trata-se de uma figura de perfis bondosos, até muito meigos. Mas com qualquer coisa de inerte.

Por isso mesmo é que Telmo constitui um eco do Velho do Restelo. Ele, que tanto fala no rei $\mathrm{D}$. Sebastião, representa um outro regresso do mundo dos mortos: o retorno do célebre personagem camoniano. De facto, Telmo é o Velho do Restelo em pantufas. A imobilidade do ancião desenhado pelo poeta épico ecoa nessa outra imobilidade de Telmo, que ao mesmo tempo é a imobilidade do povo português: uma gente presa aos seus costumes, aos seus usos; como que vivendo ainda nos seus castros, apesar de habitar cidades contemporâneas.

É claro que existe também dinamismo nas nossas raízes populares: entre o povo português, encontram-se muitos Manuéis de Sousa que se mexem, que protagonizam, por exemplo, a emigração. Contudo, no perfil de Telmo, Garrett quis representar uma certa atitude passiva, que prevalece numa grande parte da população. Existe como que uma teimosia de atavismos na figura de Telmo.

Por esse motivo é que ele tanto se opõe a Manuel de Sousa Coutinho. Os nossos grandes reformadores sempre se defrontaram com os Telmos da vida real. E é também por isso que o velho criado de D. João de Portugal é sebastianista. 
O sebastianismo representou um reflexo dessa imobilidade portuguesa ${ }^{11}$. Com a sua vivência política do nosso primeiro liberalismo, Garrett sabia muito bem o quanto esta "paragem" das nossas camadas populares detém a nossa história. Para os revolucionários de 1820, o povo português olhou do mesmo modo que Telmo olha para o seu segundo senhor, D. Manuel de Sousa Coutinho. Com um ceticismo infinito, com uma ironia incapaz de acompanhar os futuros propostos.

E tudo isto, todas estas facetas da portugalidade, o medo de Madalena, que é o nosso receio português, a iniciativa e a heroicidade de Manuel, que são também as de Portugal, a fragilidade de Maria, que é a do nosso porvir, e o imobilismo de Telmo, ainda tão presente numa boa parte do nosso povo - tudo isto convive harmoniosamente no seio de uma única família, que representa toda a nossa cultura e a nossa história.

E essa família vê-se ensombrada por um fantasma, uma aparição terrífica que vem do passado. Ora, esta perceção da história nacional como um espetro representa uma ideia essencial do autor de Frei Luís de Sousa. No contexto da obra garrettiana, o país morre no seu poema Camões, de 1825. E é talvez por isso que, em 1843, quer no drama trágico que estamos a analisar, quer em Viagens na Minha Terra, a portugalidade já nos aparece em estado de fantasma. Deste modo o autor de O Alfageme de Santarém explica-nos que a construção da nossa modernidade se perfila como uma fatalidade: morto e morrido o passado - o futuro será a única ressurreição.

Contudo, a figura do romeiro não deve ser lida só como encarnação do passado. D. João de Portugal também representa o "estrangeirado": aquele que fez o seu percurso humano fora do país - e depois não é reconhecido pelos seus, transformando-se num "ninguém" cultural. Nesse sentido, Jorge de Sena, José Rodrigues Miguéis, só para citar alguns exemplos, foram romeiros. Romeiro foi também o próprio Fernando Pessoa, ignorado enquanto esteve vivo. Todos eles nos surgem como indivíduos que palmilharam o território de desterros que a nossa cultura gera. De resto, muitos emigrantes são, cada um à sua maneira, romeiros rejeitados.

11 O sebastianismo como problema do Frei Luís de Sousa foi estudado por Luciana Stegagno Picchio, no texto desta autora já antes por nós citado. 
Eis aqui a magnífica pintura de Portugal que este livro nos deixa. Feito de retratos, este drama constitui, ele próprio, um grande fresco das atitudes espirituais fundamentais que tecem a nossa vida nacional. Enfim, encontramo-nos perante uma radiografia portuguesa. Nela, podemos contemplar o funcionamento misterioso do nosso esqueleto cultural. Por isso mesmo, Frei Luís de Sousa faz pensar nos Painéis de São Vicente de Fora. Só que a pujante nacionalidade que nos surge nesta última obra pictórica se vê substituída por uma família em crise: contudo, nos rostos dos seus membros, podemos ver os nossos próprios rostos. Tal como nas faces representadas nos painéis podemos avistar as caras que um dia tivemos.

E este representar da portugalidade não se resume a uma galeria de figuras onde identificamos as nossas virtudes cardeais e os nossos vícios inextinguíveis. Na obra, também se encena - e tão bem! - a afetividade portuguesa, a ternura que se derrama pelos gestos fora, o mel das nossas palavras ${ }^{12}$. Todo o carinho com que somos portugueses uns para os outros, quando estamos em família, se revela no texto.

Tal como se revela também, e magnificamente, o nosso viver sempre à distância, de que se tem feito a nossa história ${ }^{13}$. Muito ao longe mora a família de Madalena e de Manuel de Sousa, numa Almada da qual se avista Lisboa. Ora, é numa Almada equivalente que Portugal se tem situado, entrevendo à distância a Europa a que pertence, a Península de que faz parte e o mundo inteiro.

Admirável esta fotografia que Garrett tirou a Portugal, com o seu Frei Luís de Sousa. Fotografia esta que, como vimos, também é uma imagem de si mesmo, e dos seus dramas sentimentais mais íntimos. Assim se realizou uma perfeita fusão entre a identidade do escritor e a do país. Essa mesma concordância que se deu em todos os nossos grandes escritores: Camões, Pessoa, Antero ou Eça foram quem foram - mas nisso que eram estava também muito do que o país era.

12 É muito interessante a análise que José Régio fez do estilo do Frei Luís de Sousa, sublinhando o "magistral equilíbrio" que o caracteriza: "O problema da linguagem no Frei Luís de Sousa" in AA. VV., Estrada Larga, I, Porto, Porto Editora, s. d., pp. 314-316.

13 Partindo deste viver à distância, Eduardo Lourenço fará uma muito curiosa interpretação "política" de Frei Luís de Sousa: "Romantismo e tempo e o tempo do nosso romantismo: a propósito do Frei Luís de Sousa" in AA. VV., Estética do Romantismo em Portugal, Lisboa, Centro de Estudos do Século xix do Grémio Literário, 1974, pp. 105-11. 


\section{O enigma espiritual: o convento}

E contudo, apesar de todo este brilhantismo, apesar de constituir uma admirável fotografia de nós mesmos, Frei Luís de Sousa continua a ser um texto mal amado. Porquê? Talvez isto aconteça devido à mensagem última, de natureza espiritual, que no livro se adivinha. Uma mensagem que não nos tem sido fácil aceitar: está lá, mas não a queremos ver.

Em que consiste essa lição? Tratemos, em primeiro lugar, da proposta que este livro faz a cada pessoa. Frei Luís de Sousa diz-nos que o nosso verdadeiro destino, aquele onde encontraremos o nosso rosto em estado puro, implica uma grande solidão, uma enorme solidão conventual - que, porém, será acompanhada por Deus. Um homem que cumpre a sua vocação é como se entrasse num mosteiro.

E este processo, esta longa ascese do nosso devir biográfico, revestir-se-á de uma dimensão de dor. Com quarenta e quatro anos, Garrett aprendera isto. Não tinha família: separara-se da mulher, e Adelaide Pastor morrera em 1841. João Baptista estava só. Sabia que escrever se tornara para ele, apesar da sua fama, um percurso de secreta solidão. Tanto quisera não ser sacerdote, e os acasos conduziram-no a um estranho tipo de sacerdócio cívico e literário.

Os acasos? Não: João Baptista sentia uma força, uma energia fatal, que o empurrava - por vezes com violência. Em Frei Luís de Sousa, vive, e muito, aquela relação equívoca que o cristão mantém com a Providência. Aceita-a, mas com uma certa amargura. De facto, neste drama trágico garrettiano, afirma-se uma fé que ainda não consegue ser a alegria de si mesma. O livro acredita, mas fá-lo sem deixar de estar enovelado na sua tristeza ${ }^{14}$.

Contudo, o caminho ficou apontado - a solução é o convento. Será nesse convento que o próprio Garrett residirá desde 1843 até ao fim dos seus dias: vestido de dândi, ele é, no fundo, um frade ${ }^{15}$. Quem conhecer a biografia monumental de Gomes de Amorim sabe bem da grande solidão garrettiana -

14 Quem chamou a atenção para esta incomodidade espiritual de Frei Luís de Sousa foi precisamente Ofélia Paiva Monteiro, na sua introdução a uma edição desta peça garrettiana: "Introdução" in Almeida Garrett, Frei Luís de Sousa, Porto, Livraria Civilização Editora, 1987, pp. 24-26.

15 Devemos recordar aqui a interpretação que Agustina Bessa-Luís fez de Garrett, na obra intitulada Garrett, o Eremita do Chiado, Lisboa, Guimarães Editores, 1998. 
e também do impressionante ermamento que rodeou a morte, tão desértica, deste autor $^{16}$. E foi no secreto convento de uma biografia cada vez mais isolada que o Almeida Garrett um pouco convencional dos anos vinte e trinta do século XIX - se metamorfoseou no enorme Almeida Garrett das décadas de quarenta e cinquenta de Oitocentos. Ele próprio, por conseguinte, se transformou no Frei Luís de Sousa de si mesmo.

Também nós temos um convento à nossa espera. Cada um saberá do seu. E todos sentiremos uma força que nos empurra para lá. Entretanto, a nossa reação inicial será sombria e melancólica, perante o lugar onde, paradoxalmente, irá começar a nossa alegria. Eis um resumo do que contém o Frei Luís de Sousa como lição de vida. Só que esse magistério não se faz desde os territórios felizes da ressurreição: ele opera-se ainda entre as trevas obscuras da nossa paixão. Morre-se neste drama trágico de 1843, e ao fundo do fúnebre palco existe uma luzinha que vasqueja. A solução, porém, está lá, nessa pequena luminosidade escondida. A solução que Garrett escolheu, ou aceitou mais do que escolheu, mas que o levou a escrever as suas grandes obras - e a ser verdadeiramente quem estava destinado a ser. E esse convento que para ele funcionou também terá resultados excelentes, quando aplicado às nossas biografias.

Já repararam que o Frei Luís de Sousa, enquanto texto, enquanto produção estética, também é um convento? O facto de não ser escrito em verso, a sobriedade da sua ação, com poucas personagens - tudo aponta para uma estilização conventual. As próprias palavras desta peça de 1843 também são um mosteiro. Porque o convento não é apenas a solução para nós como pessoas - também o será para a nossa arte, para a nossa atividade. Quanto mais capazes de sobriedade, de uma límpida concisão, mais impacto terá o nosso agir. As últimas obras dos grandes artistas são sempre maravilhosamente simples. Também a arte se resolve, pois, conventualmente.

E torna-se impressionante constatar que Frei Luís de Sousa sugere ainda um mosteiro para Portugal. A solução não é apenas individual: é também coletiva. Depois de todos os nossos arabescos oníricos - de todas as nossas fantasias sebastianistas, dos nossos delírios de grandeza, brasileiros ou africanos -, o país talvez ganhasse em voltar, de uma vez por todas, à verdade de si mesmo.

16 Essa solidão é mais patente no terceiro volume de Garrett-Memórias Biográficas, obra de Francisco Gomes de Amorim: Lisboa, Imprensa Nacional, 1884. 
Aliás, a realidade atual portuguesa pede aos gritos um mosteiro. Precisamos desse mosteiro - da coragem de o assumirmos. Da sua chã e sincera sobriedade. E não deixa de ser curioso intuir que, nessa aparente derrota, triunfaríamos. Porque afinal é nas vitórias fingidas desta nossa carnavalesca modernidade que somos derrotados. Deixemos de fazer de conta, quer como pessoas, quer como portugueses. Aceitemos a nossa verdade. Na primeira parte de Frei Luís de Sousa, as personagens estão metidas num teatro que não sabem que é teatro - até que o romeiro chega. Também nós estivemos, nestes últimos anos, embrenhados no nosso teatro pessoal, e no teatro do nosso tempo. Entretanto, o romeiro bateu à nossa porta. Mas aí está, à nossa espera, o convento final de Frei Luís de Sousa, propondo-nos um regresso à nossa verdade: único modo de voltarmos a ter um futuro. 


\section{BIBLIOGRAFIA}

AMORIM, Francisco Gomes de, (1881-1884), Garrett-Memórias Biográficas, Lisboa, Imprensa Nacional, 3 tomos.

BESSA-LUÍS, Agustina, (1998), Garrett, o Eremita do Chiado, Lisboa, Guimarães Editores.

KAYSER, Wolfgang, (1970), "Interpretação de Frei Luís de Sousa" in Análise e Interpretação da Obra Literária. Introdução à Ciência da Literatura, trad. de Paulo Quintela, vol. II, Coimbra, s. e., pp. 285-300.

LOURENÇO, Eduardo, (1974), "Romantismo e tempo e o tempo do nosso romantismo: a propósito do Frei Luís de Sousa" in AA. VV., Estética do Romantismo em Portugal, Lisboa, Centro de Estudos do Século xIx do Grémio Literário, pp. 105-111.

MAGALHÃES, Gabriel, (2007), "A dobradiça mágica: uma leitura extrema de Almeida Garrett" in Estar Entre, Salamanca, Editorial Celya, pp. 139-148.

MAGALHÃES, Gabriel, (2009), Garrett e Rivas: o romantismo em Espanha e Portugal, Lisboa, Imprensa Nacional-Casa da Moeda, 2 vols..

MENDES, João, "Máscara, luz e chama, em Garrett" in Brotéria, vol. LXXXVII, n 11, Novembro de 1968, pp. 493-511.

MONTEIRO, Ofélia Paiva, (1971), A Formação de Almeida Garrett: Experiência e Criação, Coimbra, Centro de Estudos Românicos, 2 vols.

MONTEIRO, Ofélia Paiva, (1987), "Introdução" in Almeida Garrett, Frei Luís de Sousa, Porto, Livraria Civilização Editora, pp. 5-31.

PICCHIO, Luciana Stegagno, (1982), "Interprétation d'interprétations: le Frei Luís de Sousa de Garrett" in La Méthode Philologique, II, Paris, Fundação Calouste Gulbenkian/ Centro Cultural Português, pp. 263-277.

PIMPÃO, Álvaro Júlio da Costa, (1940), O Frei Luís de Sousa de Almeida Garrett, Coimbra, Universidade de Coimbra.

RÉGIO, José, "O problema da linguagem no Frei Luís de Sousa" in AA. VV., Estrada Larga, I, Porto, Porto Editora, s. d., pp. 314-316.

ROCHA, Andrée Crabbé, (1954), O Teatro de Garrett: Tese de Doutoramento em Filologia Românica pela Universidade de Lisboa, $2^{\mathrm{a}}$ ed., Coimbra, s. e.,

SOUSA, Maria Leonor Machado de, (1984), "Frei Luís de Sousa e a literatura europeia" in AA. VV., Afecto às Letras, Lisboa, Imprensa Nacional-Casa da Moeda, pp. 483-489. 